Jap. J. M. Sc. \& Biol., 11, 339-346, 1958

\title{
THE SURVIVAL OF ONCOMELANIA NOSOPHORA, THE VECTOR SNAIL OF SCHISTOSOMA JAPONICUM UNDER THE DRIED CONDITION AND THEIR WATER LOSS*
}

\author{
YoShITAKA KOMIYA AND ISAO HASHIMOTO \\ Department of Parasitology, National Institute of Health, Tokyo
}

(Received: September 26th, 1958)

On the resistance of Oncomelania nosophora to dryness, several reports are available (Cort, 1919; Yamanouchi, 1919; Bartch, 1929; Sugiura, 1933; Kawamoto, 1954). They all observed only their survival under the dried condition. Oncomelania nosophora, a Japanese vector snail of Schistosoma japonicum, however, has an amphibious character and can survive for a certain period under dried conditions. The effect of dryness on snails is considered to result in more evaporation of water from the snail body and inflict the gradual loss of water which would be the cause of their death. The purpose of this work is to know the relation between the rate of the water loss from snail body and the survival rate of the snail when put under a continuous dried condition.

\section{Materials ANd Methods}

The experiments were carried out both during the summer and winter. Snails applied in the winter experiment were collected in late October, 1957 and those applied in the summer experiment in August, 1957 at an endemic area of Yamanashi Prefecture. They were used for experiments within ten days after the collection. Before the application to experiments they all were washed with distilled water, their shells being cleansed. Then they were put on filter paper and divided into male and female according to the sex differentiating technic by observing penis through the shell. All snails except the youngest were divided into male and female groups. They were also divided into three groups according to the shell length; adult group (shell length 7-9 mm), younger group (shell length 5-7 mm) and youngest group (shell length $3-5 \mathrm{~mm}$ ). Owing to the immaturity of the sex organ, members of the youngest group could not be divided by sex.

All snails put on filter papers were found soon to close their opercula and showed no movement. Then they were weighed on each experimental group, and put into Petri dishes under a dried condition at room temperature for about 120-130 days. The temperature and humidity during the experiment were recorded by the aid of autographs.

The number of snails of each experimental group was 300 to 500 . On every tenth day after the commencement of experiments 20-40 snails were randomly taken from each group, weighed and examined. Their death was finally ascertained by dissection. The diminished

*This work was partly supported by the grant from the National Institutes of Health of U. S. A.

小宮義孝・橋本魁（国立予防衛生研究所奇生虫部） 
amount of water per snail was calculated from the difference of the weight of every two successive weighings. The rate of water loss to the weight of the dried snail body without its shell was also calculated. The procedure was as follows. The snail was crushed and, after removing its shell, the dried body was weighed. Provided that the weight of the shell is constant the total weight of the snail consists of the weight of its shell, of the dried snail body and water contained in the space between the shell and the body. Thus the weight of the totai snail minus those of shell and of the dried body is the weight of water contained in the snail.

\section{RESULTS}

\section{The Results of Experiments in Summer}

The results of the experiments in summer is shown as Fig. 1. The temperature during this experiment was $20-24^{\circ} \mathrm{C}$ (mean $21^{\circ} \mathrm{C}$ ) and the mean relative humidity $77 \%$.

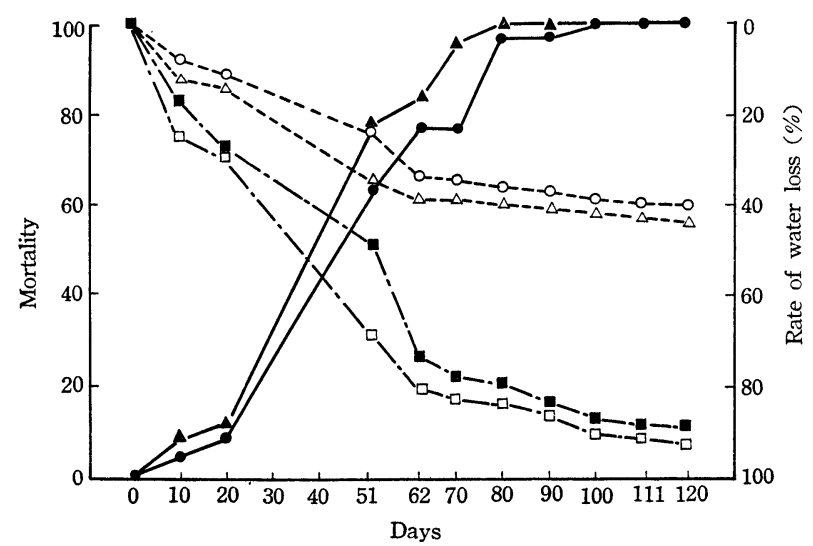

Fig. 1. Relation between the rate of water loss and the mortality of Oncomelania nosophora under the dryness (summer).

Comparison between adult and younger snail.

Mortality $\left\{\begin{array}{l}\longrightarrow \text { Adult } \\ \longrightarrow\end{array}\right.$

Water loss (excluding shell)

Water loss $\left\{\begin{array}{l}\circ \cdots \circ \text { Adult } \\ \triangle \cdots \bullet \text { Younger }\end{array}\right.$

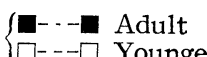

Temperature $20-24^{\circ} \mathrm{C}$. Mean temperature $21^{\circ} \mathrm{C}$.

Mean relative humidity $77 \%$.

Duration : 10 Aug. $1952 \rightarrow 9$ Dec. 1957 .

a) The survival of the adult and their water loss: Ten days after the exposure to dryness, as seen in the figure, the death rate of the adults showed $3.3 \%$ and the rate of water loss to the total snail weight at that time was $8.0 \%$; after 20 days the death rate arose to $6.7 \%$ with the water loss of $12.3 \%$; after 51 days the death rate $63.3 \%$ with the water loss of $22.5 \%$, and after 100 days the death rate reached $100 \%$ with the water loss of $40.1 \%$.

b) The survival of the younger and their water loss: Snails of this group showed $100 \%$ death rate 20 days sooner than that of the adult with the water loss of $43.1 \%$. 
They showed 20 days after exposure to dryness a death rate of $11.1 \%$ with the water loss of $13.2 \%$ and after 91 days a death rate of $77.8 \%$ with the water loss of $33.6 \%$. Owing to a hindrance the result after 40 days in this experiment could not be examined.

\section{The Results of Experiments in Winter}

The experiments on the sex difference in the survival rate under the dried condition were also carried out. Concerning this problem only the adult and the younger were used, because the sex organ in snails of the youngest group was not developed enough to enable sex differentiation. The temperature during the experiments was $10-14^{\circ} \mathrm{C}$ (mean $13^{\circ} \mathrm{C}$ ) and the mean relative humidity $60 \%$.

a) The death rate of snails of each group and the water loss: The results of experiments during the winter was Fig. 2.

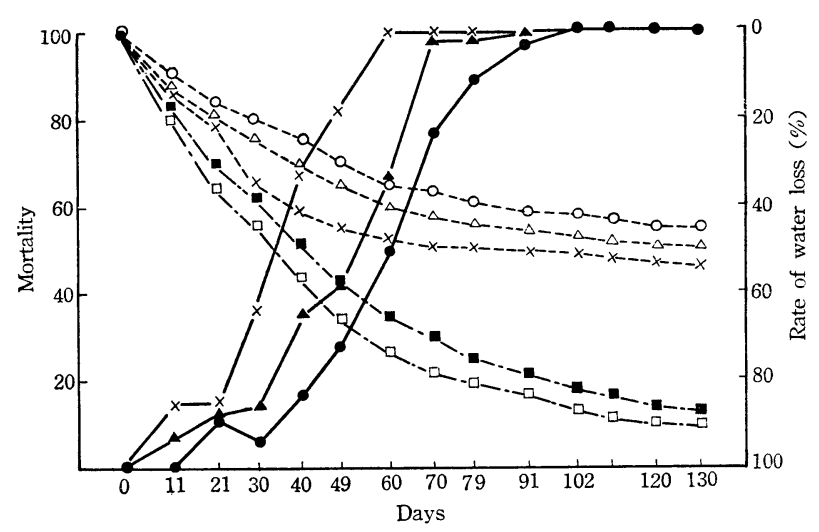

Fig. 2. Relation between the rate of water loss and the mortality of Oncomelania nosophora under the dryness (winter).

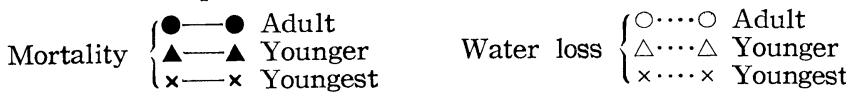

$$
\begin{aligned}
& \text { Water loss (excluding shell) }\left\{\begin{array}{l}
\square--\square \\
\square-r-\square \text { Adult } \\
\square \text { Younger }
\end{array}\right.
\end{aligned}
$$

Temperature $10^{\circ}-14^{\circ} \mathrm{C}$. Mean temperature $13^{\circ} \mathrm{C}$.

Mean relative humidity $60 \%$.

Duration: 1 Dec. $1957 \rightarrow 10$ Mar. 1958 .

i) Snails of the adult group: On the 11th days of exposure to dryness no snails were found dead. On the 21st day, however, $11 \%$ of snails were found dead with a water loss of $15 \%$. Forty days after exposure the death rate was $16.2 \%$ with $25.1 \%$ of a water loss, after 60 days the death rate $48.6 \%$ with a water loss of $34.1 \%$ and after 102 days all snails were found dead with a water loss of $43.1 \%$.

ii) Snails of the younger group: Ten days after exposure to dryness some snails (7\%) were already found dead with a water loss of $10.9 \%$, after 49 days a death rate of $41.9 \%$ and a water loss of $35.9 \%$ and after 91 days all snails were found dead with a water loss of $44.8 \%$. 


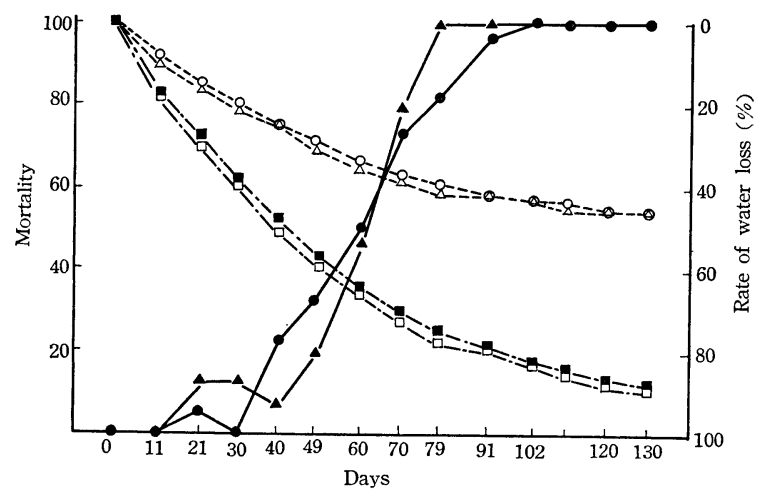

Fig. 3. Relation between the rate of water loss and the mortality of Oncomelania nosophora under the dryness (winter).

Comparison between male and female in adult snail. Mortality

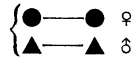

$$
\text { Water loss }\left\{\begin{array}{l}
0 \cdots 0 \\
\triangle \cdots
\end{array}\right.
$$

Water loss (excluding shell)

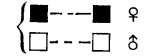

Temperature $10^{\circ}-14^{\circ} \mathrm{C}$. Mean temperature $13^{\circ} \mathrm{C}$.

Mean relative humidity $60 \%$.

Duration : 1 Dec. $1957 \rightarrow 10$ Mar. 1958 .

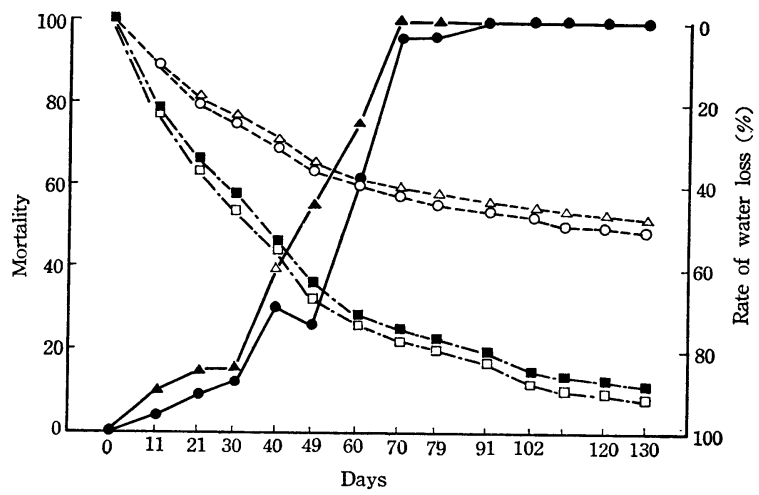

Fig. 4. Relation between the rate of water loss and the mortality of Oncomelania nosophora under the dryness (winter).

Comparison between male and female in younger snail.

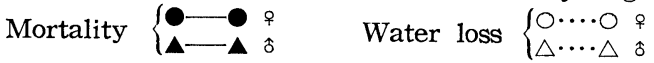

Water loss 'excluding shell) $\begin{cases}\square-- & \square \\ \square--\square & \text { o }\end{cases}$

Temperature $10^{\circ}-14^{\circ} \mathrm{C}$. Mean temperature $13^{\circ} \mathrm{C}$.

Mean relative humidity $60 \%$

Duration: 1 Dec. $1957 \rightarrow 10$ Mar. 1958.

iii) Snails of the youngest group: A death rate of $13.6 \%$ was seen 11 days after the exposure and thereafter the death rate increased remarkably as the time elapsed so as to be $81.8 \%$ on the 49 th day and $100 \%$ on the 60 th day. Thus, as 
the size of the snail became smaller, the resistance to dryness inclined to diminish. It is noted on snails of the younger group that the rate of water loss to the dried body weight could not easily be culculated because of the difficulty of removing the body from the shell.

b) Sex of snails and their resistance to dryness:

i) Sanils of the adult group: Fig. 3 shows the resistance of both sexes to dryness among snails of adult group. The male snails showed rather less resistance in an early stage, but later the time when the male showed about $50 \%$ death rate coincided with that when the female did.

ii) Snails of the younger group: As seen in Fig. 4, the male snails of the younger group also showed a lower resistance to dryness as compared with the female.

\section{Discussion}

As already seen in Fig. 2, the resistance of the adult to dryness appears to be larger than that of the younger, while the rate of water loss of the adult snails smaller than that of the younger, the fact suggesting that the water loss of snails

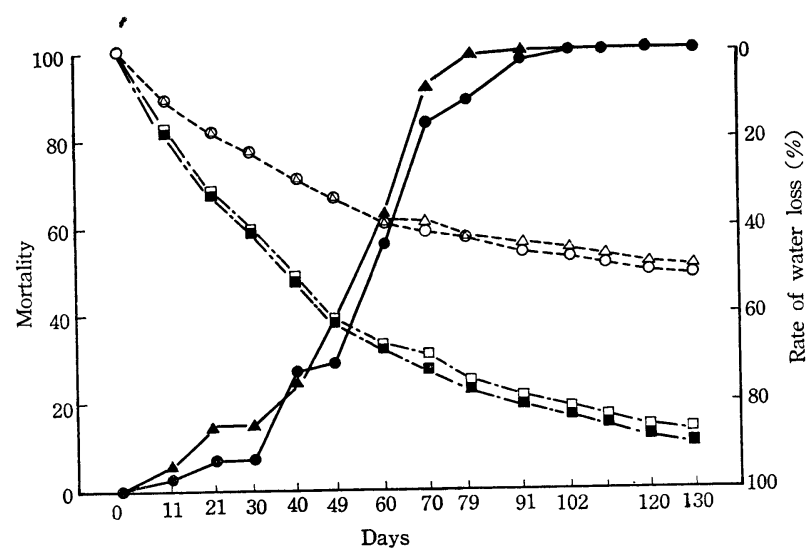

Fig. 5. Relation between the rate of water loss and the mortality of Oncomelania nosophora under the dryness (winter).

Comparison between male and female in younger and adult.

Mortality

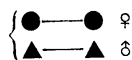

Water loss $\begin{cases}0 \cdots \odot & \text { o } \\ \triangle \cdots \cdots \triangle & \text { o }\end{cases}$

Water loss (excluding shell)

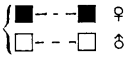

Temperature $10^{\circ}-14^{\circ} \mathrm{C}$. Mean temperature $13^{\circ} \mathrm{C}$.

Mean relative humidity $60 \%$.

Duration : 1 Dec. $1957 \rightarrow$ Mar. 1958.

is an important factor for their survival. The water contained in snails can be distinguished into two portions, one being held in the space between the shell and the snail body (outer water) and the other inside the snail body (inner water). The figures showing the rate of water loss in Fig. 2 indicate that the rate of the water loss tends to diminish as the time of exposure is prolonged. Such a tende ncy 


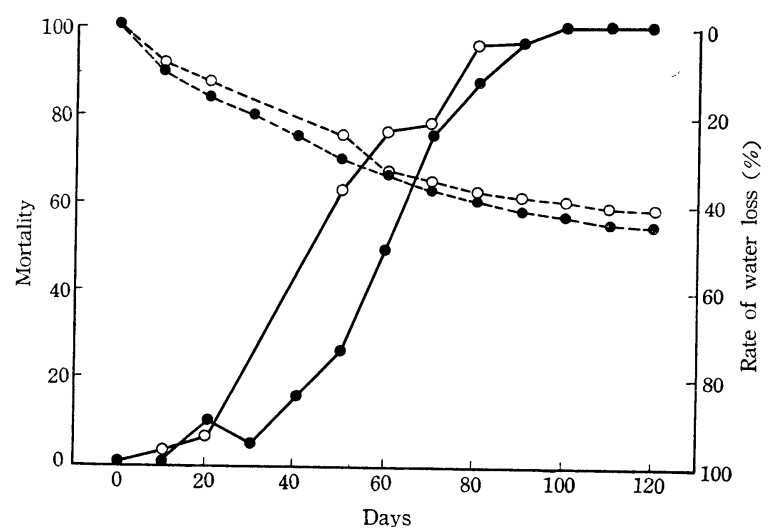

Fig. 6. Relation between the rate of water loss and the mortality of Oncomelania nosophora under the dryness.

Comparison between winter and summer in adult snail.

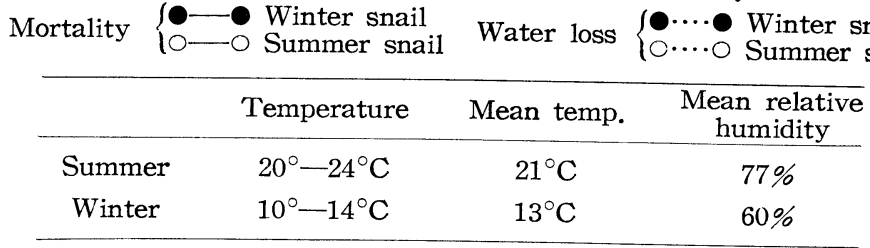

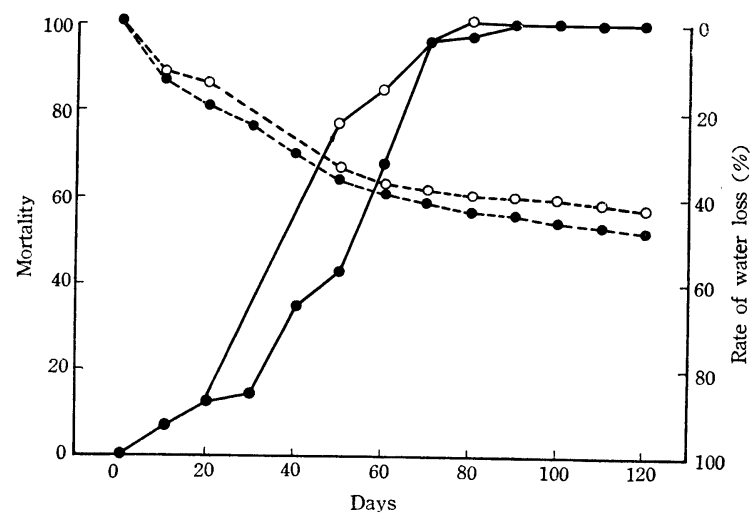

Fig. 7. Relation between the rate of water loss and the mortality of Oncomelania nosophora under the dryness.

Comparison between summer and winter in younger snail.

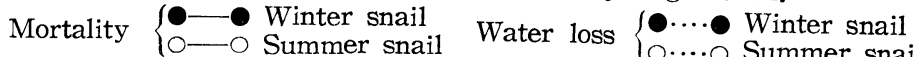

\begin{tabular}{cccc}
\hline & Temperature & Mean temp. & $\begin{array}{c}\text { Mean relative } \\
\text { humidity }\end{array}$ \\
\hline Summer & $20^{\circ}-24^{\circ} \mathrm{C}$ & $21^{\circ} \mathrm{C}$ & $77 \%$ \\
Winter & $10^{\circ}-14^{\circ} \mathrm{C}$ & $13^{\circ} \mathrm{C}$ & $60 \%$ \\
\hline
\end{tabular}


suggests that during the initial period chiefly the outer water is lost and later followed by the gradual loss of the inner water. It is considered that the shorter survival of the younger snails under the dried condition can be explained by the more rapid water loss due to more rapid evaporation.

Figs. 5, 6 and 7 show the comparison of the resistance to dryness (in adult and younger groups, respectively) between males and females and in summer and winter as well. The figures indicate that both adult and younger snails tend to show lower resistance to dryness in summer than in winter probably because of the more rapid water loss in summer, although the possible effect of hibernation in winter can not be excluded.

The problem of whether there exists sexual difference in the resistance to dryness can not be clarified yet. As far as our experiments are concerned, however, the female seems to have a rather higher resistance.

\section{SUMMARY}

To know the relation between survival of Oncomelania nosophora and its water loss under the dried condition, several experiments were carried out and the results are summarized as follows:

1. The death rate of snails under the dried condition was not so prominent up to the 40th day of the exposure but increased rather rapidly thereafter and attained $100 \%$ after 60 days with the youngest while after 80-100 days with the younger and the adult groups.

2. The water loss of the snails after the exposure to dryness was achieved rapidly up to 30 days after the exposure but afterwards became slow and after the 60 th day practically no loss of water was recognized. From that time the mortality of snails increased rapidly until it reached $100 \%$ very soon. Roughly speaking, about $40 \%$ water loss appeared to be critically detrimental for the survival of snails.

3. As compared with the adult, younger snails showed a rather lower resistance to dryness. Such a difference is considered to depend chiefly upon the difference in the water loss from them.

4. Snails showed a relatively lower resistance to dryness in summer than in winter, which is likely to have been caused by the seasonal difference in the metabolism.

5. Males appeared to show a lower resistance to dryness than the females.

\section{REFERENCES}

CORT, W. W. (1919): On the resistance to dissication of the intermediate host of Schistosoma japonicum Katsurada. J. Parasitol., 6, 84-88.

ITAGAKI, H. (1955): Anatomy of Oncomelania nosophora (Robson) (Gastropoda). The Venus, 18, 161-168.

KAWAMOTO, S. (1954): Biologicol studies on Oncomelania nosophora, an intermediate host of Schistosoma japonicum in Japan. Report II. Ecological studies. J. Kyoto Pref. Med. Univ. (text in Japanese with English summary).

KOMIYA, Y. \& YASURAOKA, K. (1953): The behavior of Oncomelania nosophora, the first intermediate host of Schistosoma japonicum, in water. Jap. J. M. Sc. \& Biol., 6, 451-461.

SugIURA, S. (1933): An intermediate host of Schistosoma japonicum. Mitt. Path. Inst. Med. Fakult. Niigata, 31, 1-18. 
YAMANOUCHI, J. (1919): Biological studies of the intermediate host of Schistosoma japonicum. "Nihon Byorigakkai Kaishi," 9, 231 (text in Japanese). 